\title{
Biofilm Associated Genotypes of Multidrug-Resistant Pseudomonas aeruginosa
}

Redfern, J' ${ }^{1}$, J. Wallace ${ }^{1}$, A. van Belkum², M. Jaillard ${ }^{2}$, E. Whittard ${ }^{1}$, R. Ragupathy ${ }^{1}$, J. Verran ${ }^{1}$, P. Kelly ${ }^{1}$, and M.C. Enright ${ }^{1}$.

${ }^{1}$ Faulty of Science and Engineering, Manchester Metropolitan University, UK.

${ }^{2}$ bioMérieux SA, La Balme les Grottes, France.

\section{Abstract}

Pseudomonas aeruginosa is a ubiquitous environmental microorganism that is also a common cause of nosocomial infections that vary in severity from chronic wound infections to pneumonia, bloodstream infections and sepsis. Its ability to survive in many different environments and persistently colonize human tissue is linked to its presence within biofilms that form on indwelling device surfaces such as plastics and stainless steel. Biofilm promotes bacterial adhesion and survival on surfaces, reduces susceptibility to desiccation, and the actions of antibiotics and disinfectants. Recent genome sequencing studies demonstrate that $P$. aeruginosa is a highly diverse species with a very large pan-genome consistent with its adaptability to differing environments. However, most MDR infections are caused by a small number of "high-risk" clones or lineages that recently emerged and spread globally.

In our 2017 study of the resistome of $P$. aeruginosa we confirmed the power of genomewide association (GWAS) techniques to explore the genetic basis of several antibiotic resistance phenotypes and discovered 46 novel putative resistance polymorphisms. In this study we sought to examine genetic associations within a subset of these isolates with simple biofilm phenotypes. We examined the genetic basis for biofilm production on polystyrene at room temperature $\left(22^{\circ} \mathrm{C}\right)$ and body temperature $\left(37^{\circ} \mathrm{C}\right)$ within a total of 280 isolates. $69 \%$ of isolates $(n=193)$ produced more biofilm mass at $22^{\circ} \mathrm{C}$, whilst those producing more biofilm at $37^{\circ} \mathrm{C}$ had reduced optical density 540 variation. We found statistically significant associations with $I p x O$ and other genes associated with arsenic resistance to be significantly associated with this trait. IpxO which encodes a lipid A hydroxylase and arsenic reduction genes have previously been found to be associated with biofilm production in this species. We analyzed 260 ST111 and ST235 genomes and found considerable genetic variation between isolates in their content of genes previously found associated with biofilm production. This is indicative of a highly variable and flexible population within these clades with frequent emergence of successful sub-lineages. Analysis 
of 48 of these isolates' ability to form biofilm on stainless steel surfaces showed that a 'good' biofilm-forming phenotype had significant intra-clone variation, independent of core genome phylogeny with pan-genome analysis, suggesting a possible association and involvement of components of the type IV secretion system. However, GWAS and panGWAS analyses yielded weaker statistical significance. This study confirms GWAS and panGWAS trait associations can be performed for biofilm phenotype and produce data in agreement with each other. This panel of 280 study isolates, matched to genomic data has potential for the investigation of other phenotypes in $P$. aeruginosa perhaps as part of a growing database / collection. A representative, curated, genome sequenced collection should increase in usefulness as it grows offering increasing statistical power.

\section{Importance}

P. aeruginosa is a major cause of multiply antibiotic infections worldwide but it is also found in many hospital and natural environments, especially aquatic ones. In this study we examined genetic polymorphism associated with biofilm production at room temperature and at body temperature, the biofilm associated gene repertoire of two major MDR clones and also genetic polymorphisms associated with biofilm production on stainless steel. Using these genome-wide and pan-genome wide association methods we identified / confirmed potential key genes involved in biofilm production and survival of $P$. aeruginosa. The study demonstrates the potential usefulness of large, genome sequenced isolate collections such as ours, to better understand the genetics underlying phenotypic diversity in this species.

\section{Introduction}

Pseudomonas aeruginosa is a mono-flagellate, Gram-negative bacterium that is present in most environments. A frequent coloniser of humans, other animals and plants, it also is a very common opportunistic pathogen able to grow at a variety of temperatures ${ }^{1}$. It is a leading cause of severe, life-threatening nosocomial human infections and the major pathogen associated with lung infections of patients with cystic fibrosis. It is has been classified as one of the major species associated with multiple antimicrobial resistance of urgent public health concern by the Infectious Diseases Society of America ${ }^{2}$, Centers for

A variety of typing methods including multilocus sequence typing $(\mathrm{MLST})^{3}$ and more recently, genomic sequencing studies ${ }^{4-7}$ have shown that $P$. aeruginosa has a non-clonal, 
80

81

82

83

84

85

86

87

88

89

epidemic population structure in which successful clones occasionally arise and are globally transmitted ${ }^{8}$. Multidrug resistant (MDR) isolates of clones associated with outbreaks of infection belonging to MLST Sequence Type (ST) 111 and ST235 are two such 'high risk' clones that have global distributions and numerous and transferable antibiotic resistances ${ }^{9}$. Isolates of these clones contain a large number of horizontally transferred $\beta$-lactamase genes ${ }^{4}$ and are highly virulent in comparison to a third, less significant clone - ST175 ${ }^{10}$.

The antibiotic resistome of both ST111 and ST235 clones have been characterised in attempts to understand relationships between antimicrobial resistance (AMR) phenotype and genotype. A genomic analysis of 87 UK isolates belonging to ST111 demonstrated divergence from a common ancestor estimated to have emerged in approximately 1965, with the majority of isolates carrying the $\beta$-lactam gene VIM- $2^{5}$. A similar analysis of 79 ST235 isolates predicted a more recently evolved clone, the ancestral genotype of which emerged around 1984, coinciding with the widespread use of fluoroquinolones for the treatment of gram-negative infections ${ }^{11}$.

Whilst understanding the relationship between a pathogen's genome, epidemiological surveillance, clinical treatment and prevention success is critically important ${ }^{12,13}, P$. aeruginosa has many phenotypic features that also promote its success as a pathogen. In common with other bacterial pathogens $P$. aeruginosa usually exists within biofilms. These are complex microbial communities associated with extracellular polymeric matrices that help bacteria resist desiccation, mechanical removal and the actions of antibiotics and disinfectants ${ }^{14}$. In human tissue, biofilm-associated $P$. aeruginosa are difficult to eradicate and represent infectious foci that can lead to serious systemic disease. $P$. aeruginosa biofilms are found at surface-liquid, surface-air and liquid-air interfaces, and are a significant clinical problem in wounds and the cystic fibrosis lung ${ }^{15}$. Polymicrobial biofilms are also recognized as important niches for MDR evolution, as they represent a significant reservoir for horizontal gene transfer within and between bacterial species ${ }^{16}$.

In addition to comprehending in vivo biofilm formation, understanding $P$. aeruginosa biofilm development and persistence on other surfaces is required. Stainless steel is the most common surface material used in many industries where control of microorganisms is important, including healthcare. Properties of stainless steel include resistance to corrosion, easiness to clean and a level of hardness likely to limit scratches and other defects ${ }^{17}$. 
114 However, many of these surfaces have been shown to allow the formation of biofilms, for

115 example in hard-to-clean locations, and those with a favourable environment, such as sinks

116 and pipes ${ }^{18}$.

118 Both ST111 and ST235 isolates have been shown to produce significantly more biofilm

119 compared to those from non-high-risk clones ${ }^{19}$ whilst being over-represented in locations

120 such as hospital sink pipes ${ }^{20}$. A recent study strongly implicates the presence of $P$.

121 aeruginosa biofilm in hospital waste-water pipes as being responsible for an outbreak of

122 infection due to MDR ST111 and ST235 in a haematology unit ${ }^{21}$. A policy promoting

123 replacement of sink units to reduce such sources of infection has now been rolled out in the

124 United Kingdom.

126 There is a need to better understand the clinical importance of biofilms in hospital 127 environments starting with how biofilm production changes when $P$. aeruginosa cells move 128 from the hospital environment to the human body. Genome Wide Association Studies 129 (GWAS) have been used to great effect in identifying genetic determinants contributing to 130 disease pathology in human medicine. Thus far, microbial GWAS and more generic Whole 131 Genome Sequencing (WGS) studies have focused on the molecular epidemiology of 132 infectious disease and particularly on associations between the genome and antimicrobial 133 resistance and / or pathogenicity. There is huge potential for such methods to help 134 understand the genetic basis of other phenotypes, such as key processes that are important 135 in microbial ecology or industrial microbiology $22,23$.

137 In this study we examine the associations between aspects of the $P$. aeruginosa pan-

138 genomes and their biofilm-producing activity at different temperatures or on stainless steel

139 and examine the genetic attributes associated with biofilm production in MDR clones ST111 140 and ST235

142 Methods

\section{Bacterial isolates and genome sequences}

144 This study analyzed two different sets of $P$. aeruginosa isolates. The first set, here-on-in 145 described as 'temperature-dependent biofilm analysis' contained 280 isolates (Supp Table 146 1), for which genomic data and antibiotic susceptibility phenotype has previously been 147 described ${ }^{7,8}$. 
149 The second set, here-on-in described as 'stainless steel biofilm analysis' contained $260 P$. aeruginosa genomes (Supp Table 2), 153 of which belong to the ST111 clone and 107 to the

151 ST235 clone. Of these, 25 ST111 and 23 ST235 isolates were used to study biofilm 152 phenotypes. All genomic data were downloaded from Genbank as fasta nucleotide

153 sequences. Bacterial strains used for biofilm phenotyping were provided by bioMérieux 154 (France) and Synthetic Genomics (USA) and were analysed in two previously published 155 studies $^{6,7}$.

\section{Construction of phylogenies}

158 Core Single Nucleotide Polymorphisms (SNPs) were identified using the KSNP3 pipeline ${ }^{24}$. 159 Kmer lengths of 21 were used for temperature-dependent biofilm analysis, whilst for 160 stainless steel biofilm analysis, kmer lengths for ST111 and ST235 were 21 and 23 161 nucleotides respectively. Kmer lengths were selected using the KCHOOSER module within 162 the KSNP3 suite. Bayesian phylogenetic analysis was performed using BEAST $2^{25}$. The 163 following conditions were set: gamma site heterogeneity model, Hasegawa-Kishino-Yano 164 (HKY) substitution model, relaxed-clock log-normal, chain length 5,000,000. BEAST 2 output 165 was summarized using TreeAnnotator with a 5\% burn in.

\section{Construction and interrogation of pan-genome}

168 All genomes were annotated using PROKKA ${ }^{26}$. Using PROKKA output, pan-genomes were 169 constructed using the Roary pan-genome pipeline ${ }^{27}$, and visualized with the interactive 170 visualization tool Phandango 28.

\section{Biofilm phenotypes}

173 Temperature-dependent biofilm analysis was carried out using standard non-modified 96-

174 well plates (Starsted, Leicester, UK). Stainless steel biofilm analysis was performed on MBEC 175 biofilm 96-well plates (Innovotech, Edmonton, Canada), with pegged lids spray coated with 176 stainless steel. The sub-micron thick stainless steel coatings were deposited onto the lid by 177 the physical vapour deposition technique of magnetron sputtering, which is widely used in 178 industry to deposit thin (sub-micron to several micron thick) metallic or ceramic 179 coatings onto a wide range of components ${ }^{29}$. The coatings were sputtered from a $300 \mathrm{~mm} x$ $180100 \mathrm{~mm} 304$ grade stainless steel target in a Teer Coatings Ltd UDP350 coating rig. 
The method for biofilm growth was a modified version of that described by Coffey and

183 Anderson $^{30}$. P. aeruginosa strains were maintained on Luria-Bertani (LB) agar (BD, Sparks,

$184 \mathrm{MD}$ ) at $4^{\circ} \mathrm{C}$. Liquid cultures were prepared by inoculating a single colony into $10 \mathrm{ml}$ of LB 185 broth (BD, Sparks, MD), and incubated at $37{ }^{\circ} \mathrm{C}$ with agitation (180 rpm). An overnight 186 culture of each strain was diluted to an optical density (OD) of 1.0540. A 1:100 inoculation in 187 sterile LB broth was made in a well of the MBEC plate base. Four wells per strain were 188 inoculated. For temperature-dependent biofilm analysis, plates were incubated without 189 shaking at either $22^{\circ} \mathrm{C}$ or $37^{\circ} \mathrm{C}$ for 48 hours.

191 For stainless steel biofilm analysis, the MBEC lid was replaced and the plate was incubated at $19237^{\circ} \mathrm{C}$ with agitation (110 rpm) for 48 hours, with a change to a new 96-well plate with $200 \mu \mathrm{l}$ 193 of sterile LB broth in each well after 24 hours. To quantify biofilms, plates or pegs were 194 gently immersed in water to remove non-adhered cells, placed in $0.1 \%$ crystal violet (Sigma, 195 Dorset) for 10 minutes then gently washed in water, twice, to remove excess stain. The plates for temperature-dependent biofilm analysis had $200 \mu \mathrm{l}$ of $30 \%$ acetic acid added to each well to solubilize stain, whereas the lid with stained pegs was placed into of a 96-well plate containing $200 \mu \mathrm{l}$ per well of $30 \%$ acetic acid (Fisher Scientific, Loughborough) for 10 minutes with agitation (110 rpm). Optical density of each well was measured at $540 \mathrm{~nm}$ with a FLUOstar Omega plate reader (BMG Labtech, Aylesbury).

\section{Trait definition}

203 In order to carry out GWAS and pan-GWAS (below), categorization of biofilm production was

204 required. For temperature-dependent biofilm analysis, isolates were split into one of two 205 traits: either producing more biofilm at $37^{\circ} \mathrm{C}$ compared to growth at $22^{\circ} \mathrm{C}$, or producing 206 more biofilm at $22^{\circ} \mathrm{C}$ compared to $37^{\circ} \mathrm{C}$. For stainless steel biofilm analysis, a "good" biofilm 207 formation trait was considered to be exhibited in strains providing an OD reading $>=0.5_{540}$, 208 whilst poor biofilm formation was considered as an OD reading of $<0.5_{540}$.

\section{Pan-genome-wide association analysis}

211 Scoary is a software tool able to provide pan-genome associations (pan-GWAS) based on 212 user-defined traits using an input (gene presence / absence) file generated by Roary ${ }^{31}$. 213 Analysis was performed independently for temperature-dependent biofilm traits as for both 214 ST111 and ST235 genomes in the stainless steel biofilm analysis. Statistical significance of 215 the associations was tested by Scoary with a Fisher's exact test, and a pairwise comparisons 
algorithm to control spurious associations from stratified populations. $P$ values were corrected for multiple comparisons using the Bonferroni adjustment. Where Scoary analysis provided genes significantly $(p<0.05)$ associated with the biofilm phenotype that had not previously been annotated in PROKKA, and therefore considered hypothetical / putative, the amino acid sequence was searched in BLASTP, and if no hit was found, assessed using the sensitive protein homology detection, function and structure prediction tool HHPred (MPI

222 Bioinformatics Tool Kit) ${ }^{32}$. The top three predictions were considered for assumed protein 223 identity and function, assuming a match probability of at least $80 \%$.

\section{SNP genome-wide association study}

226 We used PLINK v1.90b5.3 $3^{33}$ to explore SNP-based associations with user-defined traits.

227 Analysis was performed in PLINK to test case / control associations with Fisher's exact test, 228 and return Bonferroni adjustments for statistical significance. Analysis was performed 229 independently for temperature-dependent analysis as before for both ST111 and ST235 230 genomes in the stainless steel dataset using core SNP data produced by the KSNP3 pipeline.

231 SNPs significantly associated with phenotype $(p<0.05)$ where located in the genome using 232 Artemis genome browser ${ }^{34}$. Genes containing SNPs of interest were interrogated using 233 BLASTP and HHpred, with the top three predictions with a probability match of over $80 \%$ 234 considered for assumed protein function.

\section{Results and discussion}

\section{Temperature-dependent biofilm analysis}

239 Biofilm formation varied greatly between isolates at both $22^{\circ} \mathrm{C}$ and $37^{\circ} \mathrm{C}$ (Figure 1). Of the 240280 isolates studied, $69 \%(n=193)$ produced more biofilm at $22^{\circ} \mathrm{C}$ (average $\mathrm{OD}_{540}$ of 1.98 ) 241 compared to $37^{\circ} \mathrm{C}\left(\mathrm{OD}_{540}\right.$ measurement of 1.29$)$. When grown at $37^{\circ} \mathrm{C}$, isolates 242 demonstrated less variation in $\mathrm{OD}_{540}$ measures than at $22^{\circ} \mathrm{C}$ (Figure 2). Increased biofilm 243 growth phenotype at $37^{\circ} \mathrm{C}$ was widely distributed across the phylogeny (Figure 3 ).

245 Scoary analysis yielded 3,431 genes associated with the phenotypic trait of producing more 246 biofilm at $22^{\circ} \mathrm{C}$ compared to $37^{\circ} \mathrm{C}$, with only one gene passing with a significant Bonferoni $p$ 247 value (Table 1), annotated using BLASTN as IpxO, a lipid A hydroxylase gene. Lipid A is one of 248 three distinct regions of the lipopolysaccharide of $P$. aeruginosa, and although literature on 249 the gene is limited, it has been suggested that LpxO plays an essential part in the success of 250 chronic infections (e.g. cystic fibrosis) ${ }^{35,36}$. More interestingly still, IpxO has been shown to 
251 be upregulated in $P$. aeruginosa when grown at a suboptimal temperature $\left(22^{\circ} \mathrm{C}\right)$ compared

252 to growth at $37^{\circ} \mathrm{C}^{37}$. Scoary analysis also provided other genes with significance, although

253 with a Bonferonni $p$ value of just above the 0.05 cut off (Table 1 ). These included $a c r 3$, ars $C$,

$254 \operatorname{ars} R$ and $\operatorname{ars} H$, four genes involved in arsenic resistance / reduction. Presence of arsenic in

255 bacterial cells has been demonstrated to affect biofilm synthesis as well as chemotaxis and

256 motility $^{38}$, with suggestion that arsenic can prevent the switch between planktonic and

257 sessile lifestyle ${ }^{39}$.

259 PLINK analysis yielded eleven significant SNPs ( $p<0.001$ after Bonferroni adjustment) 260 associated with increased biofilm production at $37^{\circ} \mathrm{C}$ compared to $22^{\circ} \mathrm{C}$ (Table 2). The most 261 significant was a non-synonymous SNP found in the IpxO gene, the lipid A gene described 262 earlier. Four other non-synonymous SNPs were identified as significant $(p<0.001$ after 263 Bonferroni adjustment) and are present in a type 1 fimbrial gene, the marC, pilW and a 264 hypothetical gene ( $y d c V)$. It is believed that type 1 fimbrial protein plays an essential role in 265 the development of fimbrial structures, facilitiating bacterial attachement and promoting 266 biofilm formation ${ }^{40}$. The pilW is involved in the development of the type-IV pilus, widely 267 demonstrated as integral to twitching, swarming and biofilm production in Pseudomonas 268 spp ${ }^{41,42}$. marC encodes a multidrug resistance protein (homologous to $t s p R$ ), deletion of 269 which reduces type III secretion systems and motility whilst increasing biofilm production ${ }^{43}$. 270 Of the remaining SNPs, four, whilst all present within a gene, were synonymous. One SNP 271 was found in ars $\mathrm{H}$, a gene which the Scoary gene presence/absence analysis also found to be 272 of significant interest with the temperature-dependent biofilm phenotype (as described 273 earlier). Another synonymous SNP of interest was located in a gene annotated as $\operatorname{smf}-1$, a 274 fimbriae-1 gene found in Stenotrophomonas maltophilia, which shares significant similarities 275 to fimbrial adhesins found in the cupA fimbriae of $P$. aeruginosa, and has been 276 demonstrated to be important in biofilm formation ${ }^{44}$.

\section{Biofilms on stainless steel}

279 Of the isolates assessed for biofilm production on stainless steel (Figure 3), $40 \%$ ( $n=10$ out 280 of 25 ) ST111 and 52\% ( $n=13$ out of 23 ) ST235 were considered high biofilm producers. This 281 demonstrates a large intra-clone variation of the biofilm phenotype. However, there was no 282 significant difference between inter-clone variation, suggesting the intra-clone variation may 283 be a common feature of other clones. 
The BEAST 2 analysis suggests ST111 isolates diverged from a common ancestor $\cong 43$ years ago (Figure 4.a), with a pan genome of 15,488 genes. The 107 ST235 isolates had a pangenome of 15,178 genes and diverged from a common ancestor $\cong 28$ years ago (Figure 4.b), suggesting that the two clones emerged within approximately 15 years of each other. When considered alongside biofilm phenotype, those isolates sharing phylogenetic similarity display similar biofilm phenotype, except for ST235 isolates WH-SGI-V-07622 and WH-SGI-V-

291 07625, as well as isolates WH-SGI-V-07498 and WH-SGI-V-07624. Nevertheless, this analysis 292 suggests many good and poor biofilm formers are closely related, and that biofilm 293 production on stainless steel is not necessarily predictable based only on genomic analysis.

The pan-genome of biofilm genes widely described in the literature (Figure 5) has a different core vs accessory structure in each of the clones, with the majority of genes $(\approx 54 \%)$ in both clones present in less than 15\% of genomes. ST235 has a higher percentage of core genes

298 compared to ST111 (61.7\% vs 31.34\%), whilst ST111 has a larger cloud genome compared to 299 ST235 (40.3\% vs 17.02\%). This variation is down to a number of homologous genes in the 300 ST111 biofilm pan-genome e.g. pelA, ps/A, ps/B. The genes pilA and fimT were both identified 301 in the ST111 pan-genome, but not found in the ST235 pan-genome, whilst ps/C was found in ST235 but not in the ST111 pan-genome.

Scoary analysis provided 77 and 107 genes of interest for association with biofilm phenotype in ST111 and ST235 respectively although none had a Bonferonni of $p<0.05$. Of these genes, 24 ST111 and 30 ST235 genes did not provide a homology match of over $80 \%$ using HHpred, and would require further functional investigation to understand their potential association

308 with biofilm phenotype. The remaining genes were considered for predicted function that 309 might be obviously associated with biofilm formation (Table 3). ST111 had six genes with 310 potential function associated with biofilm (7.8\% of the ST111 Scoary output). Predicted 311 homology of two of these genes suggest association of the flagellum system, while one gene 312 shared $99.67 \%$ homology with $\operatorname{mot} B$, an essential gene of the $P$. aeruginosa flagellar motor. 313 Mutants containing defects in the mot gene complex have been shown to exhibit a reduced 314 or abolished motility ${ }^{45}$. Another gene shared $83.03 \%$ homology with qseC, a flagellum 315 regulator gene with demonstrated importance in biofilm production in gram negative 316 bacteria ${ }^{46,47}$. Two further genes suggest association with the type-IV pili system,. These two 317 genes share homology to a type-IV pili peptidoglycan endopeptidase (RipA - 92.55\%) and a 318 geopilin domain 1 protein (PilA - 92.32\%). Of the two remaining ST111 genes from the 
319 Scoary analysis, one gene provided $100 \%$ homology to a subtilisin-like serine protease, a cellular mechanism which, if absent, has been shown to produce lower biofilm formation and motility function in $P$. aeruginosa ${ }^{48}$. The last of the ST111 Scoary genes shares $90.64 \%$ to BamC outer membrane protein, a lipoprotein likely involved in the outer-membrane biogenesis ${ }^{49}$.

Of the ST235 Scoary analysis, five genes (4.7\% of the ST235 Scoary output) had predicted

326 function that might be obviously associated with biofilm formation (Table 3). Three of the 327 genes share structural homology with type-IV secretion systems, two as hydrolases (one 328 more specifically sharing homology with peptidoglycan endopeptidase RipA), and a third 329 sharing homology to a type-IV secretion system-like gene IcmL-like, ${ }^{50}$. The fourth gene 330 shared $98.12 \%$ homology with PilP, an essential part of the type-IV pili complex ${ }^{51}$, whilst the 331 fifth shared $95.85 \%$ homology with a flagellar transcriptional activator FlhD found in gram332 negative bacteria ${ }^{52,53}$. Whilst the Scoary pan-genome association analysis does not suggest 333 an exact gene shared between the two clones in relation to the biofilm phenotype, it does 334 emphasize the importance of the Type IV secretion systems (T4SS), with multiple genes 335 present in both analyses. It is widely accepted and demonstrated in the literature that T4SS 336 plays an important role in twitching motility (important for initial biofilm formation) as well 337 as biofilm maturation ${ }^{54,55}$. It is acknowledged that biofilm production can be a highly specific 338 trait, with environmental and mechanical changes and stresses altering the biofilm performance of a particular isolate, and so continued analysis of biofilm phenotypes in different models / environmental conditions would be beneficial.

PLINK analysis provided three SNPs of significant association with biofilm phenotype in 343 ST235, and no significant SNPs in ST111 (Table 4). Cross checking SNPs with the relevant 344 genome and BLASTP of the protein sequence shows that two of the SNPs were located in the 345 same gene, a phage virion morphogeneisis protein, whilst the third was a non-coding SNP 346 downstream of the viron morphogenesis protein. PaperBLAST ${ }^{56}$ searches provides on record 347 of the gene or a homologue having already been explored in the literature.

349 Whilst the phenotype and genotype analysis and associations described in this paper 350 provide novel insight into the relationship between non-discreet phenotypes and genotype, 351 standardization of such phenotypes are required. Currently, no agreed method exists for the 352 categorization of good or poor biofilm formers, and much of the wider biofilm literature 353 uses a dynamic range of methods and approaches to biofilm studies ${ }^{57}$. This will be essential 
354 if GWAS and pan-GWAS studies are to be utilized to better understand the genetics of

355 biofilm production.

\section{Conclusions}

358 In this study we were able to identify candidate genes in which polymorphism (or deletion) was associated with differences in temperature-dependent biofilm phenotype for $280 P$. aeruginosa isolates. The two different GWAS approaches used in this paper (SNP-based and gene presence ( absence) both resulted in the identification of similar genes, namely IpxO, fimbrial genes and genes involved in arsenic resistance. The relationship between biofilm phenotypes on stainless steel and genotype in P. aeruginosa was less clear, likely due to the smaller subset of isolates used in this study. Further work should seek to utilize GWAS and pan-GWAS studies to identify new gene targets / cellular machinery alongside functional studies such gene expression (for example RNA-seq). Our study demonstrates the importance of understanding the complex nature of $P$. aeruginosa biofilm, and that phenotypic studies in isolation and/or assumptions that biofilm phenotype is consistent across $P$. aeruginosa offers little in the way of meaningful data. Unraveling the phenotypegenotype relationship of $P$. aeruginosa will be an essential next step in understanding and preventing biofilm in the era of AMR.

\section{References}

1 Silby, M. W., Winstanley, C., Godfrey, S. A. C., Levy, S. B. \& Jackson, R. W. Infectious Diseases Society of America. Clin Infect Dis 48, 1-12, doi:10.1086/595011 (2009).

3 Curran, B., Jonas, D., Grundmann, H., Pitt, T. \& Dowson, C. G. Development of a multilocus sequence typing scheme for the opportunistic pathogen Pseudomonas aeruginosa. J Clin Microbiol 42, 5644-5649, doi:10.1128/JCM.42.12.5644-5649.2004 (2004).

4 Kos, V. N. et al. The resistome of Pseudomonas aeruginosa in relationship to phenotypic susceptibility. Antimicrob Agents Chemother 59, 427-436, doi:10.1128/AAC.03954-14 (2015).

5 Turton, J. F. et al. High-Resolution Analysis by Whole-Genome Sequencing of an International Lineage (Sequence Type 111) of Pseudomonas aeruginosa Associated with Metallo-Carbapenemases in the United Kingdom. Journal of Clinical Microbiology 53, 2622-2631, doi:10.1128/jcm.00505-15 (2015). 
$6 \quad$ Jaillard, M. et al. Correlation between phenotypic antibiotic susceptibility and the resistome in Pseudomonas aeruginosa. Int J Antimicrob Agents 50, 210-218, doi:10.1016/j.ijantimicag.2017.02.026 (2017).

$7 \quad$ Alex van Belkum, L. B. S., Matthew C. LaFave, Srividya Akella, JeanBaptiste Veyrieras, E. Magda Barbu, Dee Shortridge, Bernadette Blanc, Gregory Hannum, Gilles Zambardi, Kristofer Miller, Mark C. Enright, Nathalie Mugnier, Daniel Brami, Stéphane Schicklin, Martina Felderman, Ariel S. Schwartz, Toby H. Richardson, Todd C. Peterson, Bolyn Hubby, Kyle C. Cady. Phylogenetic Distribution of CRISPR-Cas Systems in Antibiotic-Resistant Pseudomonas aeruginosa. mbio 6, e01796-01715 (2015).

8 Pirnay, J.-P. et al. Pseudomonas aeruginosa Population Structure Revisited. PLOS ONE 4, e7740, doi:10.1371/journal.pone.0007740 (2009).

9 Oliver, A., Mulet, X., López-Causapé, C. \& Juan, C. The increasing threat of Pseudomonas aeruginosa high-risk clones. Drug Resistance Updates 2122, 41-59, doi:https://doi.org/10.1016/j.drup.2015.08.002 (2015).

10 Sánchez-Diener, I. et al. Interplay among Resistance Profiles, High-Risk Clones, and Virulence in the Caenorhabditis elegans Pseudomonas aeruginosa Infection Model. Antimicrobial Agents and Chemotherapy 61, doi:10.1128/aac.01586-17 (2017).

11 Treepong, P. et al. Global emergence of the widespread Pseudomonas aeruginosa ST235 clone. Clinical Microbiology and Infection 24, 258-266, doi:10.1016/j.cmi.2017.06.018 (2018).

12 Quainoo, S. et al. Whole-Genome Sequencing of Bacterial Pathogens: the Future of Nosocomial Outbreak Analysis. Clinical Microbiology Reviews 30, 1015-1063, doi:10.1128/cmr.00016-17 (2017).

13 Aanensen, D. M. et al. Whole-Genome Sequencing for Routine Pathogen Surveillance in Public Health: a Population Snapshot of Invasive Staphylococcus aureus in Europe. mBio 7, doi:10.1128/mBio.00444-16 (2016).

14 Rasamiravaka, T., Labtani, Q., Duez, P. \& El Jaziri, M. The Formation of Biofilms by Pseudomonas aeruginosa: A Review of the Natural and Synthetic Compounds Interfering with Control Mechanisms. BioMed Research International 2015, 17, doi:10.1155/2015/759348 (2015).

15 Hutchison, M. L. \& Govan, J. R. W. Pathogenicity of microbes associated with cystic fibrosis. Microbes and Infection 1, 1005-1014, doi:https://doi.org/10.1016/S1286-4579(99)80518-8 (1999).

16 Wendel, A. F., Ressina, S., Kolbe-Busch, S., Pfeffer, K. \& MacKenzie, C. R. Species Diversity of Environmental GIM-1-Producing Bacteria Collected during a Long-Term Outbreak. Applied and Environmental Microbiology 82, 3605-3610, doi:10.1128/aem.00424-16 (2016).

17 Verran, J. \& Redfern, J. in Handbook of Hygiene Control in the Food Industry Vol. 2 (eds Huub Lelieveld, John Holah, \& Domagoj Gabrić) Ch. 42, 651659 (Woodhead Publishing Limited, 2016).

18 Salm, F. et al. Prolonged outbreak of clonal MDR Pseudomonas aeruginosa on an intensive care unit: contaminated sinks and contamination of ultrafiltrate bags as possible route of transmission? Antimicrobial Resistance \& Infection Control 5, 53, doi:10.1186/s13756-016-0157-9 (2016). 
44119 Mulet, X. et al. Biological Markers of Pseudomonas aeruginosa Epidemic High-Risk Clones. Antimicrobial Agents and Chemotherapy 57, 5527-5535, doi:10.1128/aac.01481-13 (2013).

20 Varin, A. et al. High prevalence and moderate diversity of Pseudomonas aeruginosa in the U-bends of high-risk units in hospital. International Journal of Hygiene and Environmental Health 220, 880-885, doi:http://dx.doi.org/10.1016/j.ijheh.2017.04.003 (2017).

21 Gbaguidi-Haore, H. et al. A Bundle of Measures to Control an Outbreak of Pseudomonas aeruginosa Associated With P-Trap Contamination. Infection Control \&\#x0026; Hospital Epidemiology 39, 164-169, doi:10.1017/ice.2017.304 (2018).

22 Chen, P. E. \& Shapiro, B. J. The advent of genome-wide association studies for bacteria. Current Opinion in Microbiology 25, 17-24, doi:https://doi.org/10.1016/i.mib.2015.03.002 (2015).

23 Read, T. D. \& Massey, R. C. Characterizing the genetic basis of bacterial phenotypes using genome-wide association studies: a new direction for bacteriology. Genome medicine 6, 109-109, doi:10.1186/s13073-0140109-z (2014). phylogenetic analysis of genomes without genome alignment or reference genome. Bioinformatics 31, 2877-2878, doi:10.1093/bioinformatics/btv271 (2015). doi:10.1371/journal.pcbi.1003537 (2014).

26 Seemann, T. Prokka: rapid prokaryotic genome annotation. Bioinformatics 30, 2068-2069, doi:10.1093/bioinformatics/btu153 (2014).

27 Page, A. J. et al. Roary: rapid large-scale prokaryote pan genome analysis. Bioinformatics 31, 3691-3693, doi:10.1093/bioinformatics/btv421 (2015).

28 Hadfield, J. et al. Phandango: an interactive viewer for bacterial population genomics. Bioinformatics, btx610-btx610, doi:10.1093/bioinformatics/btx610 (2017).

29 Kelly, P. J. \& Arnell, R. D. Magnetron sputtering: a review of recent developments and applications. Vacuum 56, 159-172, doi:https://doi.org/10.1016/S0042-207X(99)00189-X (2000).

30 Coffey, B. M. \& Anderson, G. G. in Pseudomonas Methods and Protocols (eds Alain Filloux \& Juan-Luis Ramos) 631-641 (Springer New York, 2014).

31 Brynildsrud, O., Bohlin, J., Scheffer, L. \& Eldholm, V. Rapid scoring of genes in microbial pan-genome-wide association studies with Scoary. Genome Biology 17, 238, doi:10.1186/s13059-016-1108-8 (2016).

32 Zimmermann, L. et al. A Completely Reimplemented MPI Bioinformatics Toolkit with a New HHpred Server at its Core. Journal of Molecular Biology, doi:https://doi.org/10.1016/i.jmb.2017.12.007 (2017).

33 Purcell, S. et al. PLINK: A Tool Set for Whole-Genome Association and Population-Based Linkage Analyses. American Journal of Human Genetics 81, 559-575 (2007). 
34 Carver, T., Harris, S. R., Berriman, M., Parkhill, J. \& McQuillan, J. A. Artemis: an integrated platform for visualization and analysis of high-throughput sequence-based experimental data. Bioinformatics 28, 464-469, doi:10.1093/bioinformatics/btr703 (2012).

35 Moskowitz, S. M. \& Ernst, R. K. The role of Pseudomonas lipopolysaccharide in cystic fibrosis airway infection. Sub-cellular biochemistry 53, 241-253, doi:10.1007/978-90-481-9078-2_11 (2010).

36 Lam, J., Taylor, V., Islam, S., Hao, Y. \& Kocíncová, D. Genetic and Functional Diversity of Pseudomonas aeruginosa Lipopolysaccharide. Frontiers in microbiology 2, doi:10.3389/fmicb.2011.00118 (2011).

37 Termi, F. \& Michel, G. P. Transcriptome and secretome analyses of the adaptive response of Pseudomonas aeruginosa to suboptimal growth temperature. International Microbiology 12, 7 (2009).

38 Andres, J. \& Bertin, P. N. The microbial genomics of arsenic. FEMS Microbiology Reviews 40, 299-322, doi:10.1093/femsre/fuv050 (2016).

39 Marchal, M., Briandet, R., Koechler, S., Kammerer, B. \& Bertin, P. N. Effect of arsenite on swimming motility delays surface colonization in Herminiimonas arsenicoxydans. Microbiology 156, 2336-2342, doi:doi:10.1099/mic.0.039313-0 (2010).

40 Ruer, S., Stender, S., Filloux, A. \& de Bentzmann, S. Assembly of Fimbrial Structures in $<$ em $>$ Pseudomonas aeruginosa $</$ em $>$ : Functionality and Specificity of Chaperone-Usher Machineries. Journal of Bacteriology 189, 3547-3555, doi:10.1128/jb.00093-07 (2007).

41 Jarrell, K. F. \& Albers, S.-V. The archaellum: an old motility structure with a new name. Trends in Microbiology 20, 307-312, doi:https://doi.org/10.1016/j.tim.2012.04.007 (2012).

42 Otton, L. M., da Silva Campos, M., Meneghetti, K. L. \& Corção, G. Influence of twitching and swarming motilities on biofilm formation in Pseudomonas strains. Archives of Microbiology 199, 677-682, doi:10.1007/s00203-017-1344-7 (2017).

43 Zhu, M. et al. Modulation of Type III Secretion System in Pseudomonas aeruginosa: Involvement of the PA4857 Gene Product. Frontiers in microbiology 7, doi:10.3389/fmicb.2016.00007 (2016).

44 De Oliveira-Garcia, D. et al. Fimbriae and adherence of Stenotrophomonas maltophilia to epithelial cells and to abiotic surfaces. Cellular Microbiology 5, 625-636, doi:10.1046/j.1462-5822.2003.00306.x (2003).

45 Doyle, T. B., Hawkins, A. C. \& McCarter, L. L. The Complex Flagellar Torque Generator of Pseudomonas aeruginosa. Journal of Bacteriology 186, 63416350, doi:10.1128/jb.186.19.6341-6350.2004 (2004).

46 Curtis, M. M. et al. QseC Inhibitors as an Antivirulence Approach for GramNegative Pathogens. mBio 5, doi:10.1128/mBio.02165-14 (2014).

47 Novak, E. A., Shao, H., Daep, C. A. \& Demuth, D. R. Autoinducer-2 and QseC Control Biofilm Formation and In Vivo Virulence of Aggregatibacter actinomycetemcomitans. Infection and immunity 78, 2919-2926, doi:10.1128/iai.01376-09 (2010).

48 Fernández, L., Breidenstein, E. B. M., Song, D. \& Hancock, R. E. W. Role of Intracellular Proteases in the Antibiotic Resistance, Motility, and Biofilm Formation of Pseudomonas aeruginosa. Antimicrobial Agents and Chemotherapy 56, 1128-1132, doi:10.1128/AAC.05336-11 (2012). 
53849 Remans, K., Vercammen, K., Bodilis, J. \& Cornelis, P. Genome-wide analysis and literature-based survey of lipoproteins in Pseudomonas aeruginosa. Microbiology 156, 2597-2607, doi:doi:10.1099/mic.0.040659-0 (2010).

50 Segal, G., Feldman, M. \& Zusman, T. The Icm/Dot type-IV secretion systems of Legionella pneumophila and Coxiella burnetii. FEMS Microbiology Reviews 29, 65-81, doi:10.1016/j.femsre.2004.07.001 (2005).

Burrows, L. L. Pseudomonas aeruginosa Twitching Motility: Type IV Pili in Action. Annual Review of Microbiology 66, 493-520, doi:10.1146/annurevmicro-092611-150055 (2012). regulated promoters analyzed by gene array and lacZ gene fusions. FEMS Microbiology Letters 197, 91-97, doi:doi:10.1111/j.15746968.2001.tb10588.x (2001).

53 Liu, X. \& Matsumura, P. The FlhD/FlhC complex, a transcriptional activator of the Escherichia coli flagellar class II operons. Journal of Bacteriology 176, 7345-7351, doi:10.1128/jb.176.23.7345-7351.1994 (1994). for Pseudomonas aeruginosa biofilm development. Molecular Microbiology 30, 295-304, doi:doi:10.1046/j.1365-2958.1998.01062.x (1998).

55 Barken, K. B. et al. Roles of type IV pili, flagellum-mediated motility and extracellular DNA in the formation of mature multicellular structures in Pseudomonas aeruginosa biofilms. Environmental Microbiology 10, 23312343, doi:doi:10.1111/j.1462-2920.2008.01658.x (2008).

56 Price, M. N. \& Arkin, A. P. PaperBLAST: Text Mining Papers for Information about Homologs. mSystems 2, doi:10.1128/mSystems.0003917 (2017).

57 Coenye, T., Goeres, D., Van Bambeke, F. \& Bjarnsholt, T. Should standardized susceptibility testing for microbial biofilms be introduced in clinical practice? Clinical Microbiology and Infection 24, 570-572, doi:https://doi.org/10.1016/j.cmi.2018.01.003 (2018). 
bioRxiv preprint doi: https://doi.org/10.1101/713453; this version posted July 28,2019 . The copyright holder for this preprint (which was not certified by peer review) is the author/funder, who has granted bioRxiv a license to display the preprint in perpetuity. It is made available under aCC-BY-NC-ND 4.0 International license.

574

Figures and tables

575 
bioRxiv preprint doi: https://doi.org/10.1101/713453; this version posted July 28, 2019. The copyright holder for this preprint (which was

not certified by peer review) is the author/funder, who has granted bioRxiv a license to display the preprint in perpetuity. It is made available under aCC-BY-NC-ND 4.0 International license.

Table 1. Genes associated with greater biofilm growth at $22^{\circ} \mathrm{C}$ compared to $37^{\circ} \mathrm{C}$ as determined by Scoary pan-genome-wide association analysis.

578

\section{9}

\begin{tabular}{|c|c|c|c|c|}
\hline 峁 & 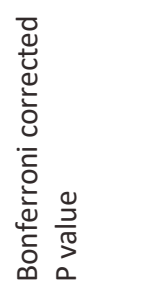 & $\begin{array}{l}\frac{0}{2} \\
\sum_{0}^{2} \\
0 \\
\frac{1}{10} \\
\frac{\pi}{2}\end{array}$ & 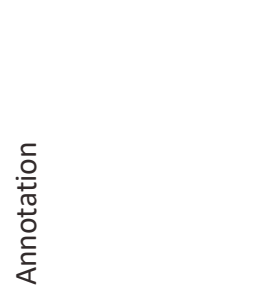 & 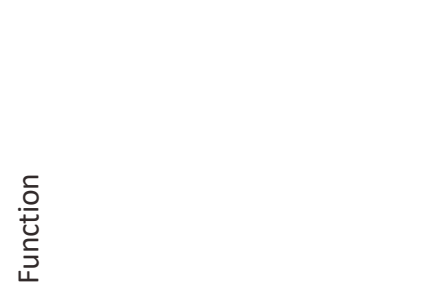 \\
\hline IpxO_1 & 0.03419409 & $1.08 \mathrm{E}-06$ & $\begin{array}{l}\text { Lipid A hydroxylase } \\
\text { LpxO }\end{array}$ & $\begin{array}{l}\text { Integral component of cellular } \\
\text { membrane }\end{array}$ \\
\hline IpxO_2 & 0.05942534 & $1.88 \mathrm{E}-06$ & $\begin{array}{l}\text { Lipid A hydroxylase } \\
\text { LpxO }\end{array}$ & $\begin{array}{l}\text { Integral component of cellular } \\
\text { membrane }\end{array}$ \\
\hline IpxO & 0.06039183 & $1.91 \mathrm{E}-06$ & $\begin{array}{l}\text { Lipid A hydroxylase } \\
\text { LpxO }\end{array}$ & $\begin{array}{l}\text { Integral component of cellular } \\
\text { membrane }\end{array}$ \\
\hline $\operatorname{arsC} 1$ & 0.07764851 & $2.45 \mathrm{E}-06$ & Arsenate reductase & $\begin{array}{l}\text { reduces arsenate to arsenite } \\
\text { Integral component of cellular } \\
\text { membrane }\end{array}$ \\
\hline acr_3 & 0.11612236 & 3.67E-06 & $\begin{array}{l}\text { Arsenical-resistance } \\
\text { protein }\end{array}$ & $\begin{array}{l}\text { Part of integral component of } \\
\text { membrane } \\
\text { Involved in transmembrane } \\
\text { transport }\end{array}$ \\
\hline $\operatorname{arsR}$ & 0.11612236 & $3.67 \mathrm{E}-06$ & $\begin{array}{l}\text { transcriptional } \\
\text { regulator }\end{array}$ & $\begin{array}{l}\text { DNA-binding transcription factor } \\
\text { activity }\end{array}$ \\
\hline $\mathrm{IpxO}$ & 0.11612236 & 3.67E-06 & $\begin{array}{l}\text { Lipid A hydroxylase } \\
\text { LpxO }\end{array}$ & $\begin{array}{l}\text { Integral component of cellular } \\
\text { membrane }\end{array}$ \\
\hline arsH & 0.11612236 & 3.67E-06 & $\begin{array}{l}\text { Arsenical resistance } \\
\text { NADPH-dependent } \\
\text { FMN reductase ArsH }\end{array}$ & $\begin{array}{l}\text { Involved in oxidation-reduction } \\
\text { process } \\
\text { Enables oxidoreductase activity }\end{array}$ \\
\hline
\end{tabular}


bioRxiv preprint doi: https://doi.org/10.1101/713453; this version posted July 28, 2019. The copyright holder for this preprint (which was

not certified by peer review) is the author/funder, who has granted bioRxiv a license to display the preprint in perpetuity. It is made available under aCC-BY-NC-ND 4.0 International license.

582

583

584

585

Table 2. SNPs found statistically ( $p<0.05$ using the Fisher exact test with Bonferroni adjustment) associated with more biofilm growth at $22^{\circ} \mathrm{C}$ compared to $37^{\circ} \mathrm{C}$ using PLINK. Base number relates to SNP position in isolate WH-SGI-V-07049.

\begin{tabular}{|c|c|c|c|c|c|c|}
\hline$\sum_{n}^{n}$ & 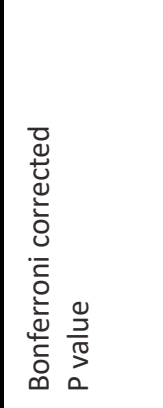 & 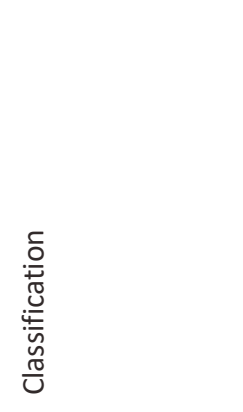 & 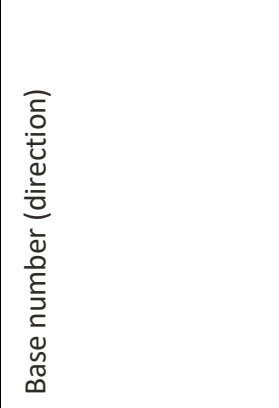 & 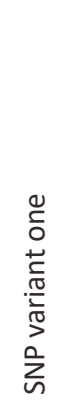 & 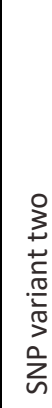 & 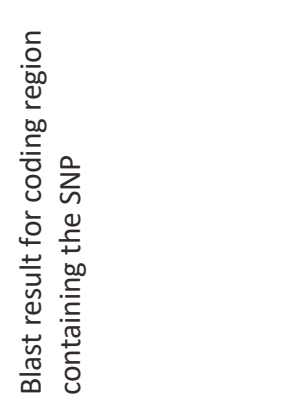 \\
\hline CCCGATGCGC.GGCGCCGTTC & $1.52 \mathrm{E}-07$ & Non-synonymous & $5,340,240$ (reverse) & G & $T$ & IpxO \\
\hline CCTGCAGAAC.CCGGGAAGAA & $9.77 \mathrm{E}-06$ & Non-synonymous & $3,288,081$ (forward) & G & A & Type I Fimbrial protein \\
\hline AACTGGTCAG.TCGGTCGGAC & $1.27 \mathrm{E}-05$ & Non-synonymous & $1,327,097$ (reverse) & C & $T$ & ydcV \\
\hline GCAGCCCTTG.GGCGACGGGA & $4.18 \mathrm{E}-05$ & Non-synonymous & 4,997,1780 (reverse) & G & $T$ & marc family protein \\
\hline AGGAGGCCTA.CAGCGTCTCC & $7.56 \mathrm{E}-05$ & Non-synonymous & $5,995,683$ (reverse) & T & c & PilW \\
\hline CGAGGCGCTG.AAGAGCGCTC & $8.92 \mathrm{E}-05$ & Not in a gene & $1,418,740$ (forward) & & & \\
\hline CGCCCTGCTG.TGAACAAGCA & $9.33 \mathrm{E}-05$ & Synonymous & $5,974,394$ (reverse) & $\mathrm{T}$ & C & hypothetical \\
\hline GCGCAGCGCC.GCCATAGGCA & 0.0003472 & Not in a gene & 4,211,288 (forward) & & & \\
\hline AGATCAAGGA.GTGCGCGCCG & 0.0003916 & Synonymous & $6,237,835$ (forward) & A & G & $\begin{array}{l}\text { fusA } 2 \\
\text { elongation factor }\end{array}$ \\
\hline AGGGCAAGAC.CTGGCGGTGA & 0.000442 & Synonymous & $2,169,567$ (forward) & C & G & $\begin{array}{l}\text { arsH } \\
\text { arsenical resistance }\end{array}$ \\
\hline AGCATTTCAC.ACCCTGTTCC & 0.0007363 & Synonymous & $6,299,006$ (forward) & c & T & $\begin{array}{l}\text { smf-I } \\
\text { major fimbrial subunit }\end{array}$ \\
\hline
\end{tabular}


bioRxiv preprint doi: https://doi.org/10.1101/713453; this version posted July 28,2019 . The copyright holder for this preprint (which was not certified by peer review) is the author/funder, who has granted bioRxiv a license to display the preprint in perpetuity. It is made available under aCC-BY-NC-ND 4.0 International license.

Table 3. Genes found statistically associated (unadjusted $p<0.05$ ) with biofilm phenotype using Scoary pan-genome-wide association analysis, for both ST111 or ST235.

589

\section{Gene ID}

Percentage similarity

\section{ST111}

\begin{tabular}{l|l|l}
\hline Group_6254 & Subtilisin-like serine protease & 100 \\
\hline Group_8277 & PomB/MotB/ompA-like - involved in flagellar motor & 99.67 \\
\hline Group_6216 & Type-IV pili peptidoglycan endopeptidase (RipA) & 92.55 \\
\hline Group_1372 & Geopilin domain 1 protein; pilin, PilA, bacterial nanowire & 92.32 \\
\hline Group_2185 & BamC outer membrane protein assembly factor & 90.64 \\
\hline Group_8212 & Sensor protein qseC & 83.03 \\
\hline ST235 & \\
\hline Group_107 & Type-IV secretory hydrolase & 99.95 \\
\hline Group_752 & Type-IV pili peptidoglycan endopeptidase (RipA) & 95.1 \\
\hline Group_3943 & PilP protein & 98.12 \\
\hline Group_859 & IcmL-like; type IV secretion system protein & 97.13 \\
\hline Group_5868 & Flagellar transcriptional activator flhD/AcaD & 95.85 \\
\hline
\end{tabular}


bioRxiv preprint doi: https://doi.org/10.1101/713453; this version posted July 28, 2019. The copyright holder for this preprint (which was not certified by peer review) is the author/funder, who has granted bioRxiv a license to display the preprint in perpetuity. It is made available under aCC-BY-NC-ND 4.0 International license.

Table 4. SNPs and related genes belonging to ST235 which have been found statistically ( $p<0.05$ using the Fisher exact test with Bonferroni adjustment) associated with biofilm phenotype using PLINK genome-wide association analysis. Base number relates to SNP position in WH-SGI-V-07627.

\begin{tabular}{|c|c|c|c|c|c|c|c|c|}
\hline$\sum_{n}^{0}$ & 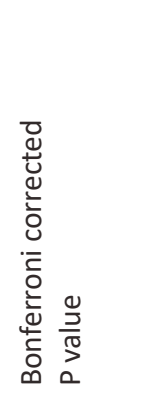 & 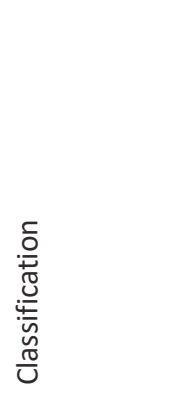 & 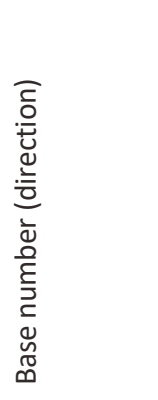 & 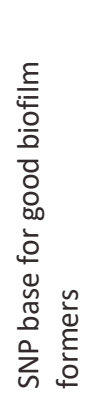 & 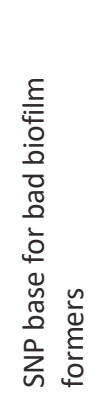 & 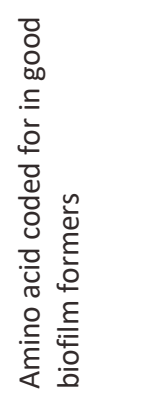 & 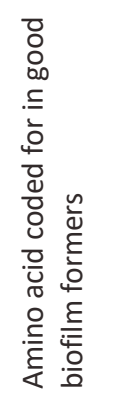 & 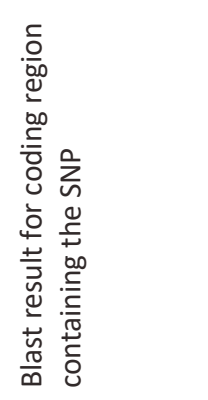 \\
\hline $\begin{array}{l}\text { CATGCTCA } \\
\text { GG.TGGAA } \\
\text { TGTGA }\end{array}$ & 0.006687 & $\begin{array}{l}\text { Non- } \\
\text { synonymous }\end{array}$ & 657,864 (f) & $T$ & C & Threonine & Alanine & $\begin{array}{l}\text { Pseudomonas } \\
\text { phage tail fiber } \\
\text { protein }\end{array}$ \\
\hline $\begin{array}{l}\text { GACGCCGC } \\
\text { TG.GCATA } \\
\text { ACGGA }\end{array}$ & 0.006687 & Synonymous & $657,937(f)$ & C & T & Alanine & Alanine & $\begin{array}{l}\text { Pseudomonas } \\
\text { phage tail fiber } \\
\text { protein }\end{array}$ \\
\hline $\begin{array}{l}\text { AGCGGCCA } \\
\text { CG.GTACAT } \\
\text { GCTC }\end{array}$ & 0.04681 & Noncoding & $657,850(f)$ & & & & & \\
\hline
\end{tabular}



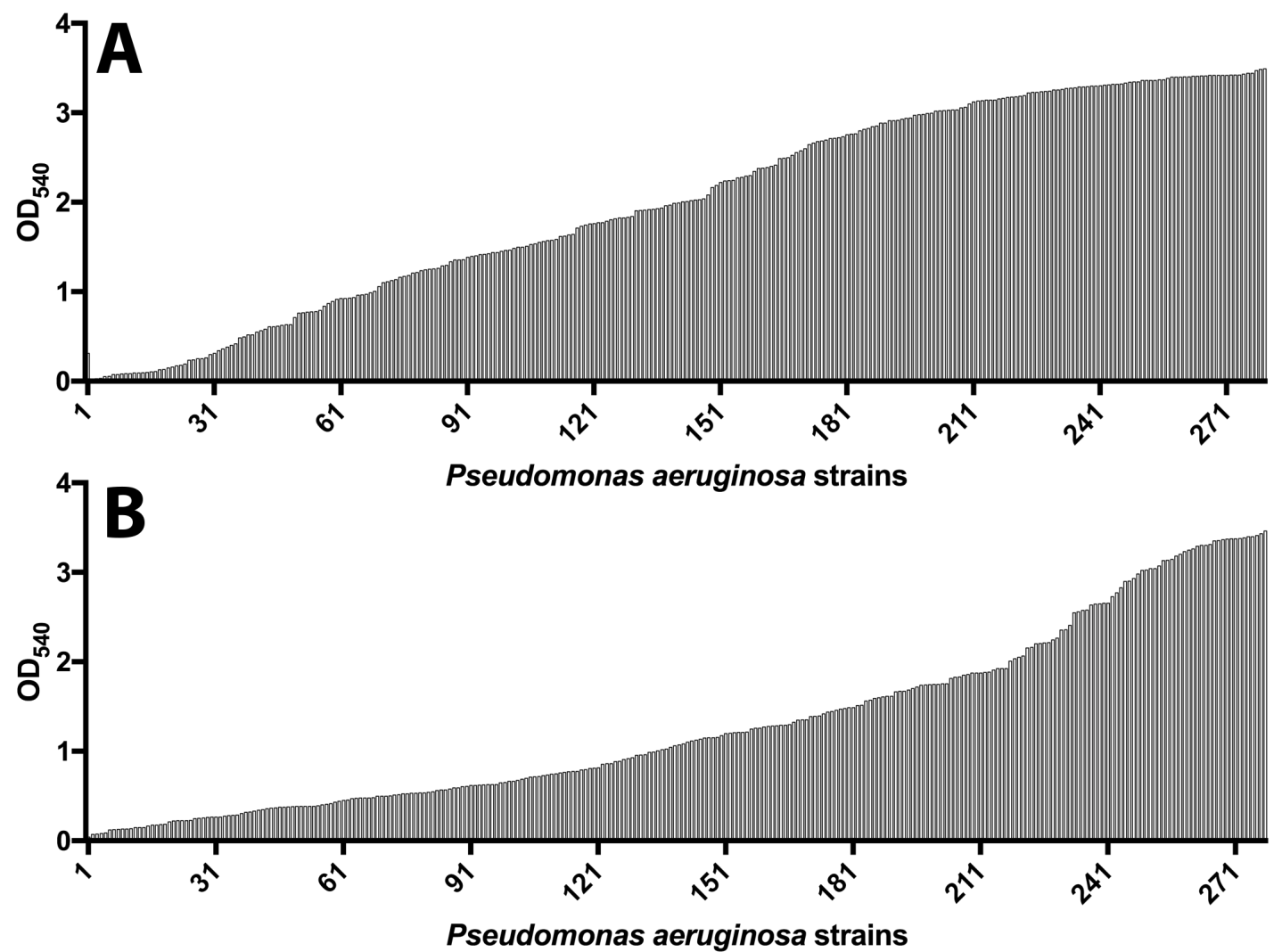
in $30 \%$ acetic acid at either $22^{\circ} \mathrm{C}$ (A) or $37^{\circ} \mathrm{C}$ (B) for 280 Pseudomonas aeruginosa isolates.

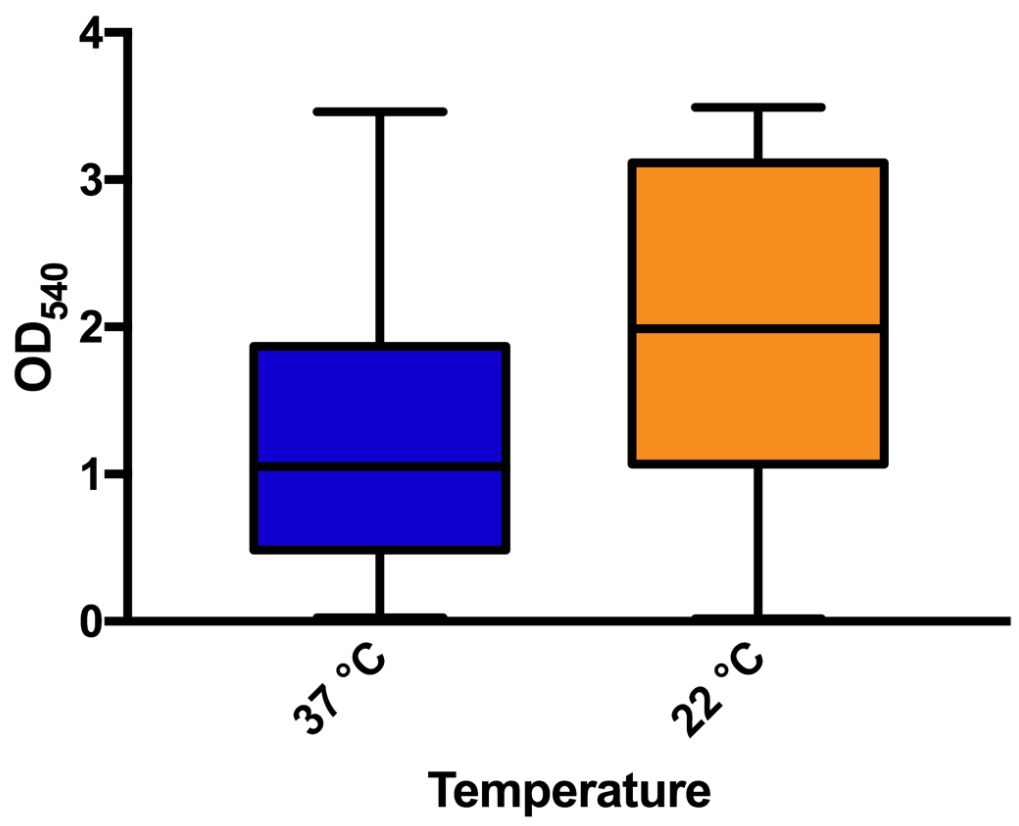

Figure 2. Box plot demonstrating the variation in biofilm formation for 280 Pseudomonas aeruginosa isolates at two different temperatures as measured by optical density. 


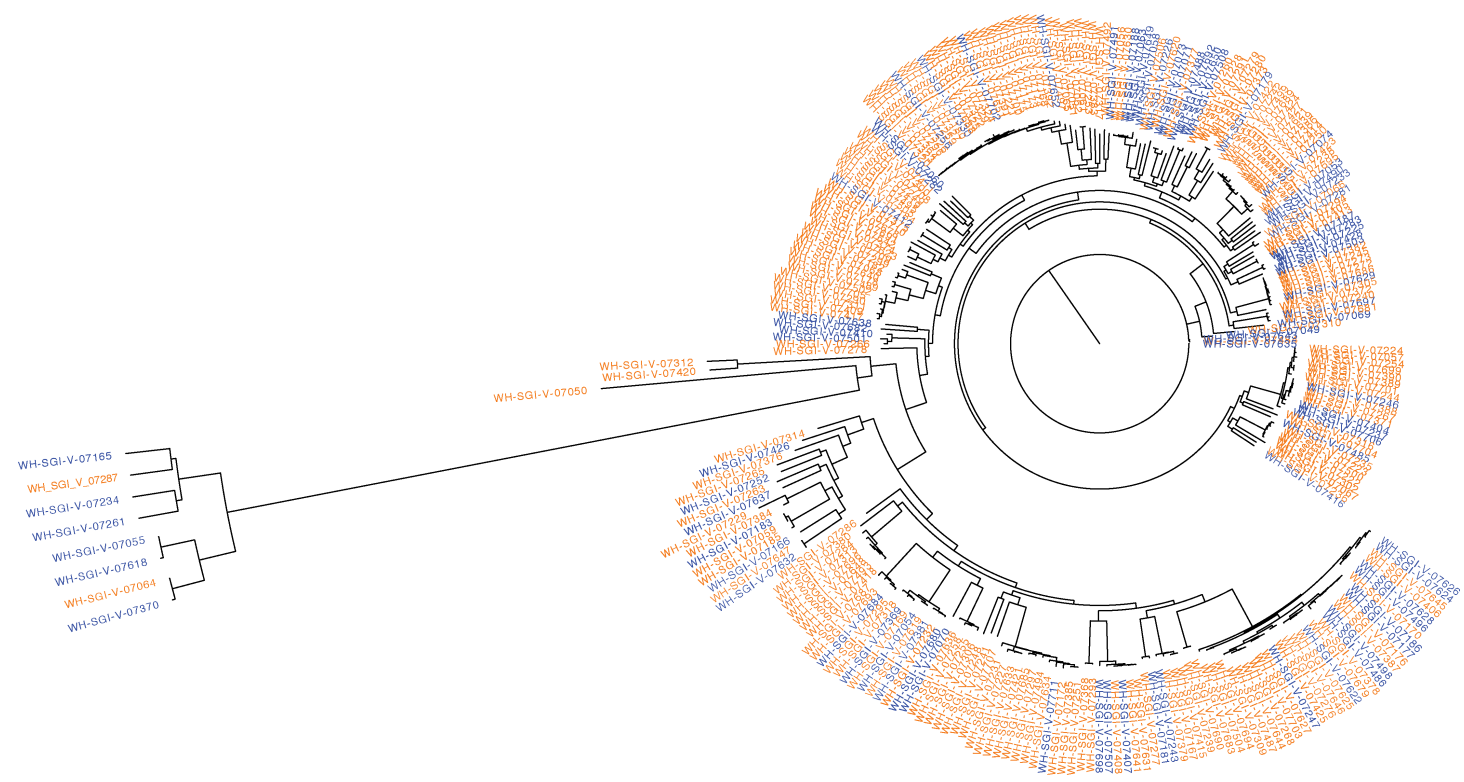

610 Figure 3 -Maximum parsimony tree (from KSNP3 analysis) of 280 Pseudomonas aeruginosa isolates. Names highlighted orange represent an isolate that produced more biofilm at 22 

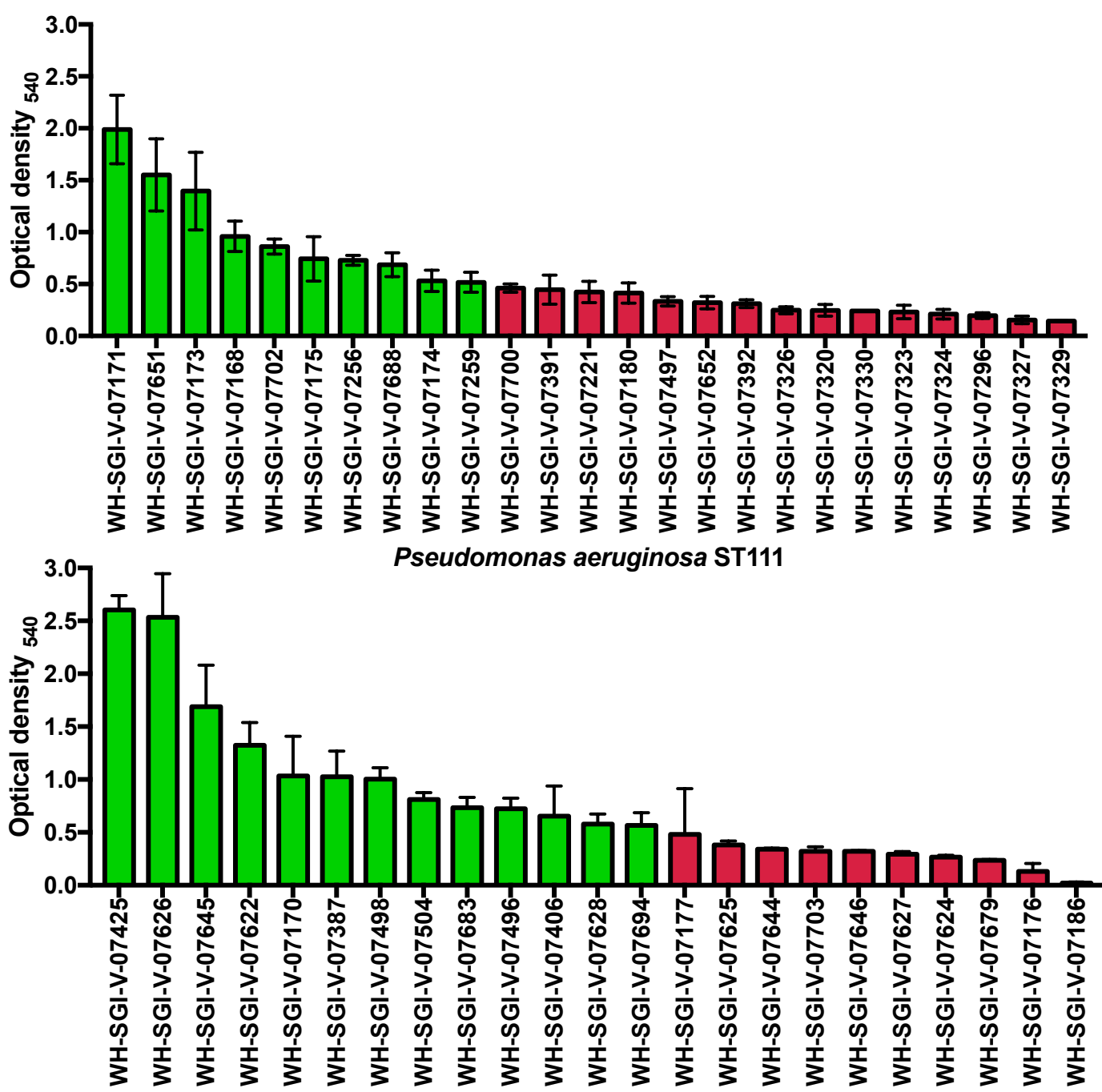

Pseudomonas aeruginosa ST235

Figure 4. Optical density readings at $540 \mathrm{~nm}$ of Pseudomonas aeruginosa biofilm after staining with $0.1 \%$ crystal violet and solubilised in $30 \%$ acetic acid. Biofilms were grown on a modified MBEC assay plate, of which the pegs had been coated in stainless steel. Data represent 25 ST111 (A) and 23 ST235 (B) strains. An optical density cut off of $0.5_{540}$ was used to differentiate high (green) and poor (red) biofilm producers. 

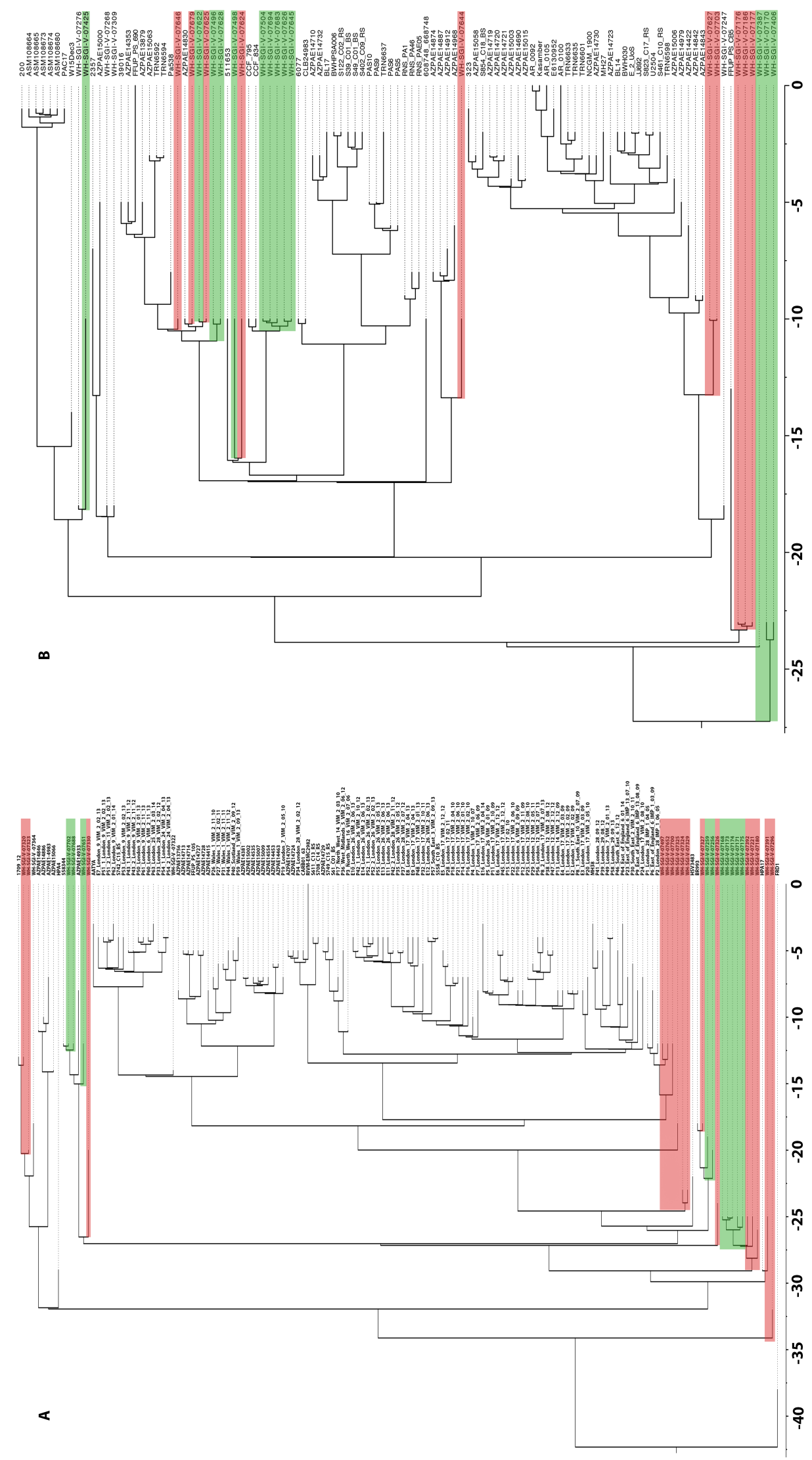
bioRxiv preprint doi: https://doi.org/10.1101/713453; this version posted July 28, 2019. The copyright holder for this preprint (which was not certified by peer review) is the author/funder, who has granted bioRxiv a license to display the preprint in perpetuity. It is made available under aCC-BY-NC-ND 4.0 International license.

621 Figure 5. Bayesian evolutionary analysis sampling tree (BEAST 2) analysis representative of 622 the ST111 (A) and ST235 (B) strains included within analysis. Horizontal distance is 623 indicative of time in years, with 0 representing the most recent isolate (2017). Strains 624 included in the biofilm on stainless steel phenotype assay (figure 4) are overlaid with their 625 designated phenotype - high biofilm producers (green) and poor biofilm producers (red). 

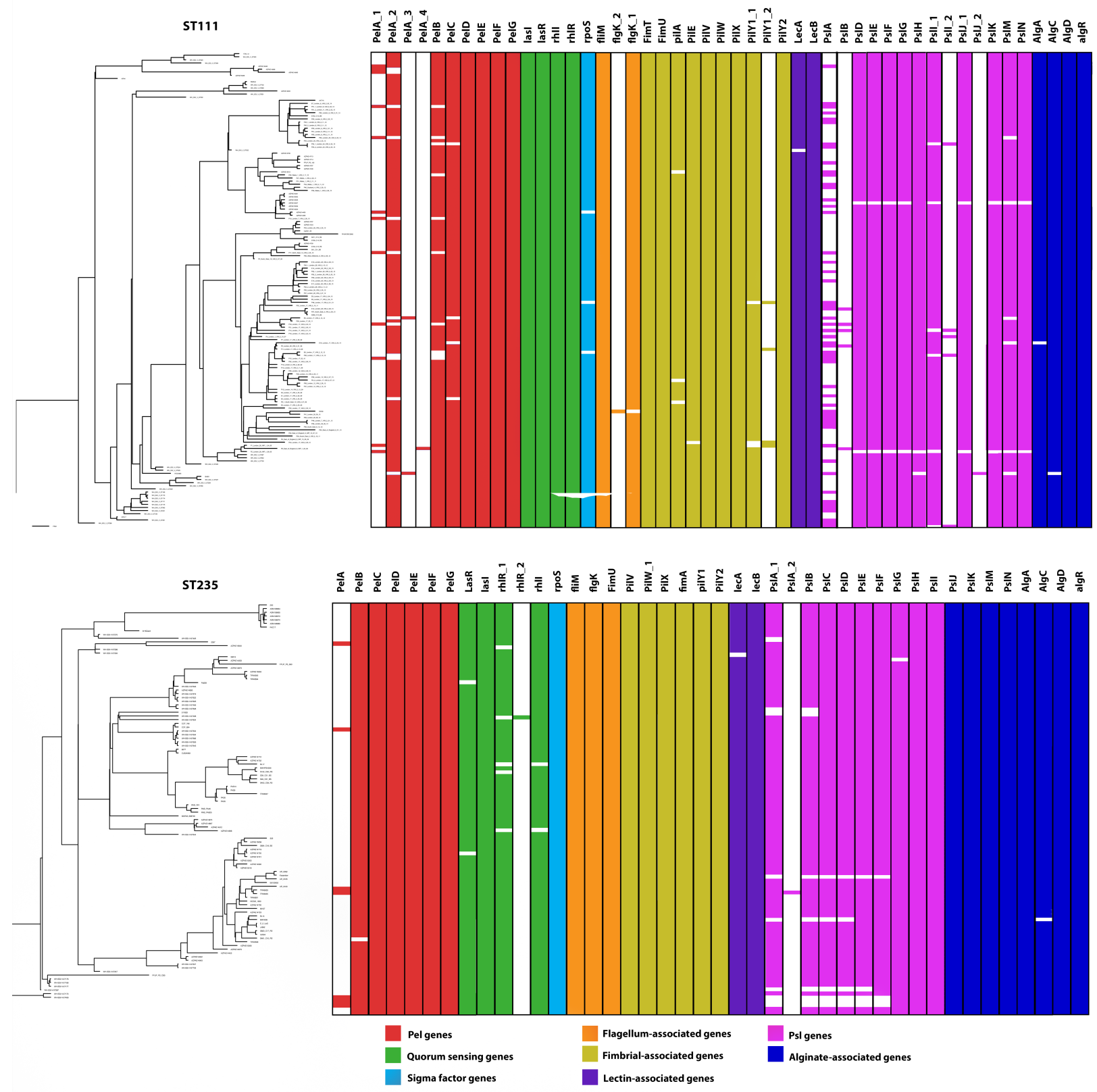

Figure 6. Biofilm gene presence/absence aligned with BEAST 2 analysis for ST111 (top) and ST235 (bottom) isolates (from Figure 2). Coloured blocks represent 48 ST111 and 42 ST235 genes that have previously been linked to biofilm formation in the literature, whilst white space represents gene absence. Colour of each block indicates gene families or biofilm features described in figure legend. 